\title{
A UTILIZAÇÃo de Plantas PELOS PESCADORES, COLETORES E CAÇADORES PRÉ-históricos da Restinga de Saquarema, Rio de Janeiro, BrasiL ${ }^{*}$
}

Lina Maria Kneip ${ }^{* *}$

\begin{abstract}
Resumo
(A utilização de plantas pelos pescadores, coletores e caçadores pré-históricos da restinga de Saquarema, Rio de Janeiro, Brasil) Este estudo apresenta alguns resultados das pesquisas arqueológicas e interdisciplinares desenvolvidas em sítios arqueológicos tipo "sambaqui", localizados no município de Saquarema, estado do Rio de Janeiro. Enfatizando na análise a utilização de plantas silvestres pelos pescadores, coletores e caçadores pré-históricos da área de restinga situada entre a lagoa de Saquarema e o oceano Atlântico, observou-se que a coleta vegetal seria bem intensa tanto para fins alimentares quanto econômicos. Correlacionando tipos de cobertura vegetal (botânica) e unidades de paisagens (geologia), foi possível compor o quadro paisagístico contemporâneo às ocupações humanas. As análises antropológicas foram de fundamental importância. A pesquisa cobre um período de tempo que vai de $4520 \pm 190$ a $1790 \pm 50$ anos A.P.
\end{abstract}

Palavras-chave: sambaqui, ocupação pré-histórica, arqueologia, Saquarema, Brasil.

\section{Abstract}

(The use of plants by prehistoric fishermen, collectors and hunters from the beach ridge of Saquarema, Rio de Janeiro, Brazil) This study shows some of the results of the archaelogical and interdisciplinary research done in archaelogical sights such as the mounds in Saquarema, in the State of Rio de Janeiro. In the analysis emphasis was given to the use of sylvan plants by prehistoric fishermen, collectors and hunters of the beach ridge area located between Saquarema lagoon and the Atlantic Ocean. It was observed that the collection of plants were very intense for food and economic purposes. After establishing a relationship between vegetation cover (botany) and units of landscape (geology), it was possible to set up the contemporary landscape picture of human occupation. The anthropological analyses were fundamentally important. The research covers the period from $4520 \pm 190$ to $1790 \pm 50$ years B.P.

Key words: mound, prehistorical settlement, archeology, Saquarema, Brazil.

\section{INTRODUÇÃO}

A região dos Lagos Fluminenses, localizada na porção setentrional do estado do Rio de Janeiro, é formada por baixadas litorâneas bastantes similares entre si. Entre essas similaridades podem ser destacadas: as direções predominantes de serras e espigões que as delimitam e que as seccionam; a presença de corpos arenosos alongados, mais ou menos paralelos às atuais linhas de praia, o que naturalmente induz a aceitar a hipótese de estarem aferidos às antigas linhas de costa; a existência de dunas atestando a ação dos ventos na área; as grandes lagoas localizadas à retaguarda das praias, destacando-se feições atuais e sub-atuais que nelas se repetem, como esporões e praias; a penetração da água do mar e a saída de água oriunda do continente através de canais, localizados nas extremidades das baixadas, que ligam lagoas ao mar, e eventuais rompimentos de barra que permitem um contato mais amplo entre o mar e as lagoas; a natureza dos sedimentos nelas encontrados; e, ainda, a interferência de que cada uma delas pode ser classificada dentro de uma etapa de um mesmo processo evolutivo (Kneip \& Marques 1975). Nesse quadro natural inserese a área arqueológica do recôncavo da lagoa de Saquarema, onde são encontrados sítios de grupos pescadores, coletores e caçadores préhistóricos, representados pelos sambaquis, em diferentes posições, datados de $4520 \pm 190$ a $1790 \pm 50$ anos A.P. (Fig. 1, Tab. 1).

Artigo recebido em 05/2008. Aceito para publicação em 02/2009.

*Este artigo foi escrito pela autora antes de seu falecimento em 2002. As notas foram escritas pela pesquisadora Viviane S. Fonseca-Kruel. Pesquisa vinculada ao projeto "Culturas Pré-Históricas do Município de Saquarema, RJ" (KNEIP coordenação), apoiada pelo CNPq, FAPERJ e Prefeitura Municipal de Saquarema.

$* * \dagger$ Arqueóloga do Departamento de Antropologia do Museu Nacional/UFRJ. Bolsista do CNPq. 


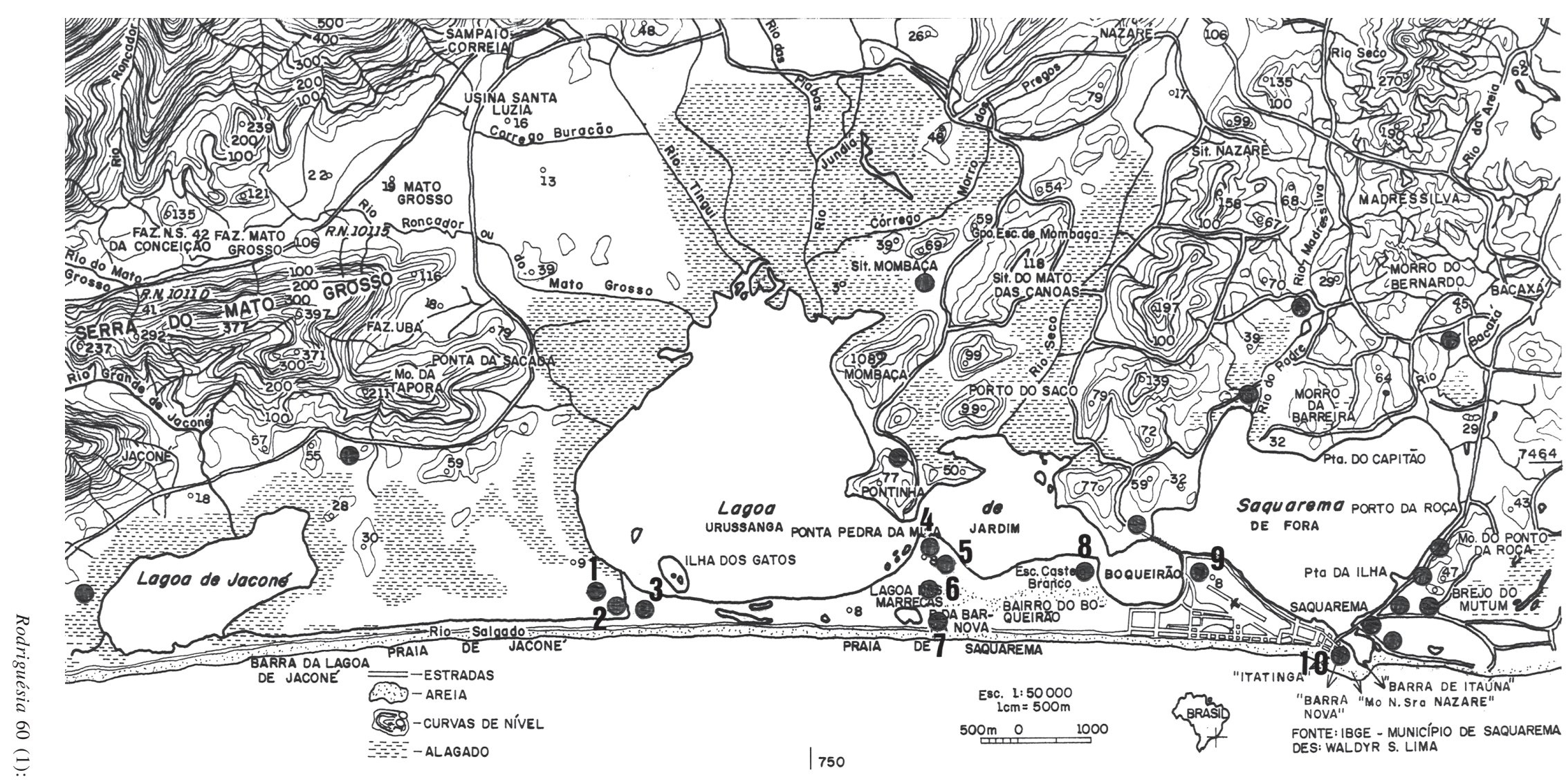

Figura 1 - Mapa arqueológico de Saquarema com localização (de 1 a 10) dos Sambaquis da região de restinga: 1 - Jaconé; 2 - Manitiba II; 3 - Manitiba I; 4 - Mário Nunes; 5 Pontinha; 6 - Beirrada; 7 - João Alves Muniz; 8 - Boqueirão; 9 - Ponte do Girau; 10 - Saquarema. 
Tabela 1 - Datações dos sambaquis de Saquarema. A.P. - Antes do Presente

\begin{tabular}{lcccl}
\hline Sambaquis & Camadas & Carbono-14 A.P. & N $^{\mathbf{0}}$ Amostra & Laboratório \\
\hline Beirada & I & $3.800 \pm 190$ & Bah-1765 & UFBa, Brasil \\
& II & $4.160 \pm 180$ & Bah-1646 & \\
& III & $4.300 \pm 190$ & Bah-1647 & \\
Moa & IV & $4.520 \pm 190$ & Bah-1651 & \\
& I & $3.610 \pm 190$ & Bah-1762 & Brasil \\
Saco & II & $3.960 \pm 200$ & Bah-1763 & \\
Madressilva & Inferior & $3.540 \pm 50$ & Gif-10654 & \\
Pontinha & Inferior & $3.640 \pm 50$ & Gif-10655 & Gif-sur-Yvette, França \\
& II & $1.790 \pm 50$ & Gif-8682 & \\
& III & $1.810 \pm 40$ & Gif-8683 & \\
Saquarema & IV & $2.270 \pm 170$ & Bah-1764 & UFBa, Brasil \\
& II & $2.550 \pm 60$ & GX-20512 & Krueger, U.S.A. \\
\hline
\end{tabular}

A lagoa de Saquarema, composta por quatro lagunas ou "sacos" denominados Urussanga, Jardim, Boqueirão e Fora, é separada do oceano por uma formação de restinga de largura variável, sobre a qual se instalaram estrategicamente sucessivos assentamentos humanos. Há $4520 \pm$ 190 anos A.P., no sambaqui da Beirada, teve início o povoamento do litoral de Saquarema. Os grupos pré-históricos localizaram-se preferencialmente na restinga situada entre a lagoa e o mar, usufruindo das riquezas naturais disponíveis, bem como da vegetação típica local que cobre ainda hoje grande parte da faixa arenosa. Sobre as areias de restinga se instalaram dezenas de ocupações humanas sambaquis de Jaconé, Manitiba II, Manitiba I, Mário Nunes, Pontinha, Beirada, João Alves Muniz, Boqueirão, Ponte do Girau e Saquarema (Fig. 1). Outros grupos preferiram ocupar as margens norte e leste da lagoa de Saquarema, à entrada de anfiteatros, em situação de baixa encosta, relativamente distantes dos recursos vegetais oferecidos pela restinga-em contrapartida dispunham das florestas de encostas e interflúvios - mas alcançada facilmente por embarcação. As populações pré-históricas de Saquarema conheciam algum tipo de embarcação para atravessar a lagoa de uma margem para a outra, ampliando consideravelmente a área de exploração de recursos.
Em grande parte dos sambaquis do litoral brasileiro, quer pelas condições climáticas geralmente não favoráveis à conservação de vestígios vegetais (no caso de Saquarema um clima semi-úmido com calor bem distribuído o ano todo) quer pela grande quantidade de restos faunísticos como ossos de peixes e conchas de moluscos, mais resistentes e de maior conservação, o estudo dos vegetais não tem merecido a atenção necessária ${ }^{1}$. Os dados relativos à dieta alimentar dos grupos litorâneos indicam sempre maior consumo de peixes, às vezes

\footnotetext{
${ }^{1}$ Scheel-Ybert (2001) ressaltou que apesar do grande interesse dos arqueólogos no ambiente das populações de pescadores-coletadores-caçadores brasileiros, e suas dietas, muito pouco é conhecido. Restos de plantas desidratadas ou secas, raramente são recuperadas nesses sítios arqueológicos, mas carvão, uma valiosa fonte de informação paleoambiental, é usualmente abundante. Com isto, a autora estudou seis amostras da costa sudeste do Rio de Janeiro, e analisou mais de 15500 fragmentos de carvão que mostraram que essa região foi coberta por diferentes associações de plantas durante o final do Holoceno, e que não houve variações significativas afetando a vegetação nesse período. Ressalta ainda que observações paleontológicas sugerem que a coleta de madeira morta forneceu a maioria do combustível de madeira usado pelo homem. Coleta de alimento vegetal foi certamente mais importante para essas populações do que previamente pensado. $\mathrm{O}$ grande número encontrado de frutos de palmeira carbonizados, sementes e tubérculos de monocotiledônias atestam sua importância na dieta humana.
} 
predominando os moluscos, complementando a alimentação com os recursos da caça e coleta vegetal.

Dados etnográficos relativos à utilização de vegetais por grupos caçadores-coletores têm demonstrado sua grande importância na alimentação. Um exemplo clássico é o estudo de Lee (1968) sobre os Kung Bushmen Botswana do deserto de Kalahari na África, que observa que $60 \%$ a $80 \%$ da dieta alimentar deste grupo caçador-coletor era proveniente da coleta vegetal. Tenório (1992), objetivando mostrar a importância da coleta de vegetais no litoral brasileiro antes da introdução da agricultura, seleciona 58 sítios arqueológicos verificando que 21 apresentavam restos vegetais dos quais 11 encontravam-se em áreas inundáveis, concluindo que o fator ambiental é de fundamental importância na preservação desses vestígios.

A exploração dos vegetais pelas populações pré-históricas de Saquarema está documentada diretamente nos restos vegetais carbonizados, carvões encontrados nas fogueiras e nos sepultamentos cremados; indiretamente nas marcas de esteios de sustentação de unidades

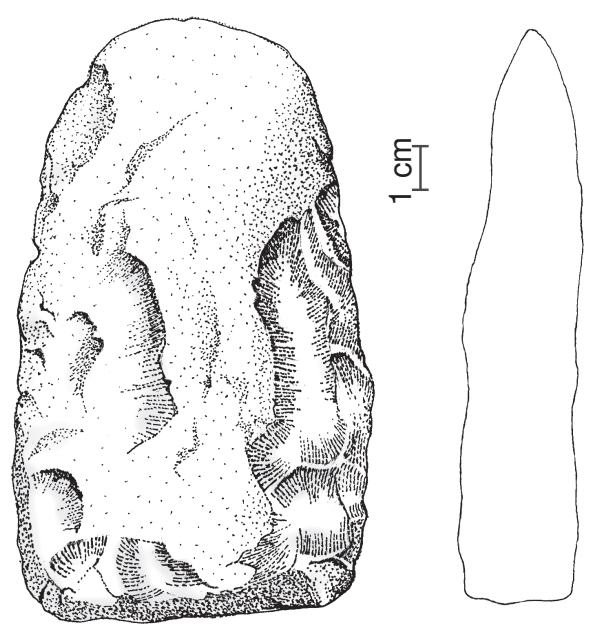

Figura 2 - Lâmina de machado lascada e polida de diabásio. Sambaqui do Moa. habitacionais, instrumentos líticos utilizados para fender (lâmina de machado) e trabalhar a madeira (enxó), recipientes de pedra onde eram esmagados os cereais (almofariz) e quebradas as sementes de certas palmeiras (quebracoquinho) (Figs. 2-5).

\section{Materiale Métodos}

Desde 1987, objetivando o estudo da forma de adaptação de culturas pescadoras, coletoras e caçadoras pré-históricas litorâneas, foi iniciado no município de Saquarema um projeto de pesquisa interdisciplinar com a colaboração de especialistas das áreas da arqueologia, antropologia biológica, botânica, geologia e zoologia.

Objetivando reconstituir o paleoambiente contemporâneo às ocupações humanas, os dados relativos à flora constituíam dados de fundamental importância, não só para avaliar a importância dos vegetais na alimentação do homem, como também inferir seus usos nas atividades quotidianas. Embora o estudo do pólen em achados arqueológicos tenha possibilitado inúmeras informações relativas a rituais, início da agricultura e modificações da

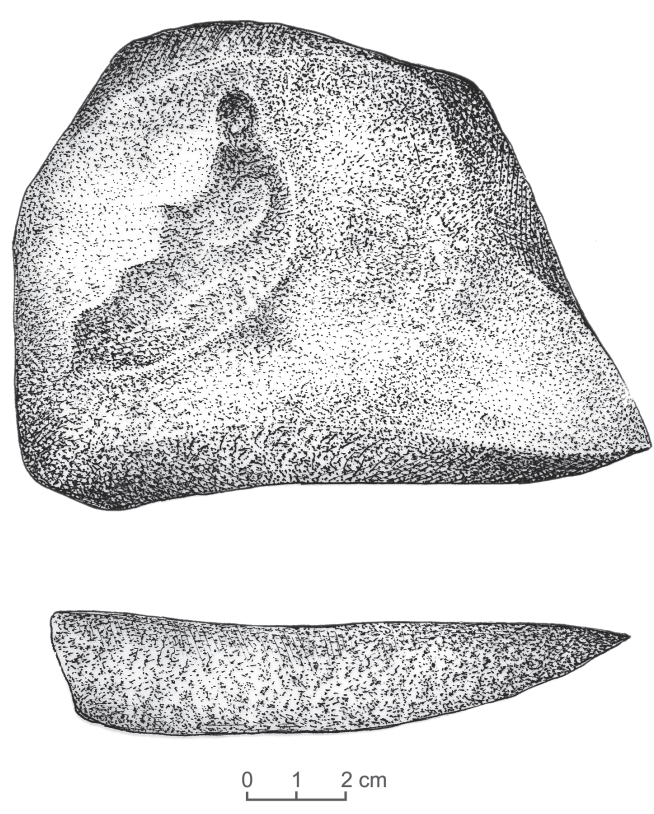

Figura 3 - Enxó. Sambaqui de Manitiba I. 


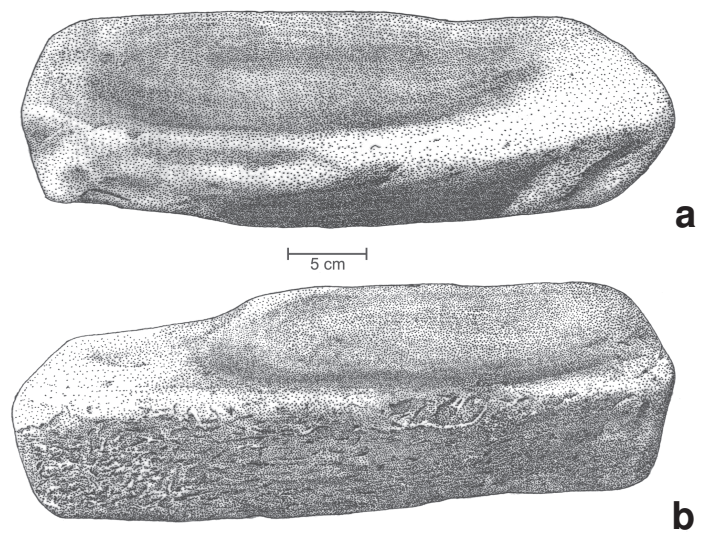

Figura 4 - Almofariz de diabásio medindo 40,0 x 15,0 x $9,5 \mathrm{~cm}$, face interna (a) e externa (b). Sambaqui do Moa.

vegetação, sua aplicação em sambaquis não tem sido recomendada pelos especialistas da área. Aliás, coletas de sedimentos realizadas através de sondagens no sambaqui de Camboinhas-Niterói, RJ (Kneip 1979), visando a análise polínica, apesar de cuidadoso trabalho de campo e de laboratório não lograram bons resultados. Tendo em vista que os sedimentos ideais para a recuperação do pólen são em geral finamente granulados e escuros por seu conteúdo orgânico (Melhem 1978), tais características não estão presentes nos sambaquis que pesquisamos no litoral do estado do Rio de Janeiro.

A fim de identificar os recursos vegetais presentes à época das ocupações préhistóricas, dois procedimentos metodológicos foram adotados:

1. Classificação dos tipos de cobertura vegetal da região de Saquarema em floresta ombrófila densa, floresta de baixada, floresta inundada, brejo herbáceo e floresta de restinga (Kneip et al. 1995), que variou de acordo com as unidades de paisagens diferenciadas em planícies flúvio-marinha-lagunares, linhas de cristas praiais e serras litorâneas (Ferreira $e t$ al. 1992). O levantamento etnobotânico foi realizado por V.S. Fonseca, tendo como referencial a região de Jacarepiá-Saquarema; por V.S. Fonseca, D.S. Araújo e C.F.C. Sá na Praça do Sambaqui da Beirada-Saquarema.

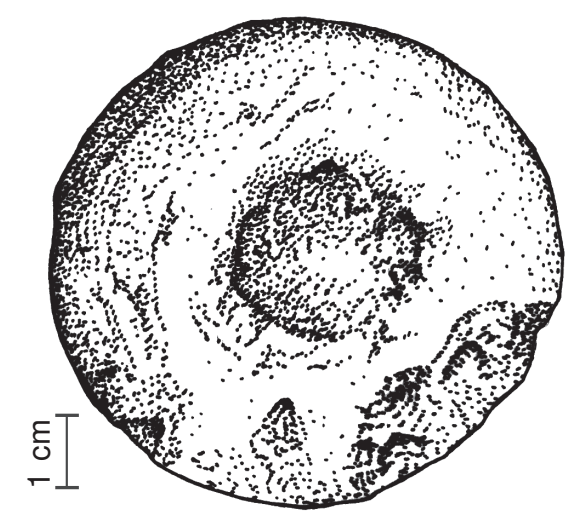

Figura 5 - Quebra-coquinho. Sambaqui da Beirada.

Do ponto de vista botânico efetuou-se o levantamento da vegetação atual remanescente nos ambientes lagunar e litorâneo, e avaliação da utilidade da flora para o homem préhistórico. A abordagem integrada botânicageologia foi de extrema importância tendo em vista que o histórico geológico da área em estudo influenciou no passado e influencia hoje a composição florística e fisionomia da vegetação.

2. Scheel-Ybert (1998) realiza pela primeira vez em território brasileiro análises antracológicas de sete sambaquis do litoral do estado do Rio de Janeiro, sendo dois em Saquarema, os sambaquis da Beirada e Pontinha (Fig. 1). Sendo a antracologia o estudo e a interpretação dos restos de madeira carbonizados provenientes de solos ou de sítios arqueológicos, a autora coleta sedimentos nos sambaquis da Beirada e Pontinha, numa área medindo $2 \mathrm{~m}$ de largura por $50 \mathrm{~cm}$ de profundidade, em perfis expostos pelas escavações, que depois de peneirados foram acondicionados em sacos para posterior triagem dos carvões e estudos laboratoriais. Os resultados das análises de carvões indicaram para Saquarema um meio vegetal com forte predomínio de elementos de restinga aberta, alguns elementos de floresta atlântica e de mangue. Encontra nos sítios analisados fragmentos de coquinhos carbonizados, sementes e resíduos de tubérculos. 


\section{Resultados e Discussão}

As populações pré-históricas litorâneas, tais como os grupos indígenas atuais, possuíam conhecimentos apurados sobre a potencialidade das plantas silvestres. Transformar uma planta tão venenosa como a mandioca em alimento, segundo Lévi-Strauss (1986), implica conhecimento de técnicas exploratórias refinadas que vão muito além da simples recoleção de espécies. Do ponto de vista arqueológico a identificação taxonômica de espécimes vegetais de valor alimentar, medicinal e econômico são dados ainda raros na pré-história brasileira.

As plantas coletadas, além de servirem como alimento, teriam inúmeros outros usos na vida do homem litorâneo: madeira para os esteios de sustentação das cabanas, fogueiras, canoas, cabos de ferramentas como no machado, arcos e hastes das flechas, lanças; fibras para amarração, cordas, trançados, fios, cestarias; resinas para a pintura corporal; cabaças para servir de recipiente; gramíneas para a cobertura das cabanas, entre outras inúmeras utilidades.

O território de pesca, coleta animal e vegetal e caça dos habitantes pré-históricos de Saquarema se estendia até $10 \mathrm{~km}$ do local de assentamento, obtendo o homem os recursos vegetais provenientes não só da restinga como também da floresta ombrófila densa, fluvial com floresta de baixada, lagunar com floresta inundada e brejo herbáceo, locais onde o homem caçava ou capturava mamíferos terrestres, aves, répteis e anfíbios.

Focalizando neste estudo a importância da vegetação de restinga para o homem préhistórico de Saquarema, podemos abordar o tema da seguinte forma:

a) Identificação da flora remanescente do ambiente litorâneo de Saquarema com base na análise integrada geologia-botânica, complementando com o levantamento etnobotânico. Em linhas gerais na restinga em questão existe uma segura e rica fonte de recursos para a alimentação do homem préhistórico ${ }^{2}$. Destes destacam-se: "Manihot tripartida - "aipim brava", Rheedia brasiliensis ${ }^{3}$
- "bacopari", Cereus fernambucensis - "caldo", Selenicereus setaceus - "caldo-maná", Eugenia copacabanensis - "caboim", Allophylus puberulus - "camboim-da-baia", Pilosocereus arrabidae - "cardeiro", Diospyros inconstans - "caqui selvagem", Campomanesia $s p$ - "guabiroba", Allagoptera arenaria "guriri”, Inga maritima - "ingá-do-grande", Opuntia brasiliensis ${ }^{5}$ - "jumbeba", Passiflora $s p$ - "maracujá", Pereskia aculeata - "ora-pronobis", Eugenia uniflora - "pitanga", Eugenia nitida - ("pitangubá, pitangão") e Sideroxylon obtusifolium - "queixabeira" (Kneip et al. 1995).

Da mesma forma entre as espécies de maior frequiência destacam-se algumas fornecedoras de matéria-prima como fibras, madeiras e corantes, provavelmente utilizadas pelo homem pré-histórico: “... tingir (redes) como Schinus terebinthifolius ("aroeira vermelha"), e outras de uso doméstico, como Senna pendula ("maio") que serve para fazer canudos, Bombacopsis glabra ("paina") para enchimento; algumas também fornecem fibras para trançar cestos, tecer, cordas para amarrar, como Philodendron corcovadense e Philodendon bipennifolium ("cipó imbé"), Arrabidaea sp. (“cipó-úna-da-restinga"). São ressaltadas espécies de madeira utilizada para lenha, como, Albizia polycephala ("chapéu-de-sol"), Bombacopsis stenopetala ("caixeta"), Pterocarpus rohrii ("jacarandá-branco, jacarandá-sangue") Machaerium hirtum ("maria-mole, sete-capa"), esta última também possui uma resina avermelhada, Caesalpinia echinata ("pau-brasil"), do qual pode-se extrair corante, Astronium graveolens ("ubatã"),

\footnotetext{
${ }^{2}$ Scheel-Ybert (1999) e Fonseca-Kruel \& Peixoto (2004) registraram estas mesmas espécies e citação de uso alimentar, no passado e presente desta região.

${ }^{3}$ Garcinia brasiliensis Mart. (táxon atual).

${ }^{4}$ Nas restingas dos municípios de Saquarema e Arraial do Cabo (Fonseca-Kruel \& Peixoto 2004) pode-se encontrar homonomia, ou seja, um mesmo nome popular para designar plantas de diferentes espécies, como "camboi" Myrciaria floribunda e Eugenia arenaria; bem como "caldo" - espécies do gênero Cereus, e Sideroxylon obtusifolium que também pode ser reconhecido por "sapotiaba, saputiquiaba".

${ }^{5}$ Brasilopuntia brasiliensis(Willd.) A. Berger (táxon atual). ${ }^{6}$ Eugenia neonitida Sobral.
} 
madeira leve, serve para fabricar caixas, caixões. As madeiras para cabo de implemento (rígida) são Pouteria psammophila ("bapuã"), Aspidosperma parvifolium ("ipequeá"), Chrysophyllum lucentifolium ("imbiú, pequiá"), madeira para construção Parapiptadenia pterosperma ("cabuíbranco"), e Pseudopiptadenia contorta ("cabuí-do-preto"), Inga fagifolia ("farinhaseca"), Posoqueria latifolia ("folha-larga"), Aspidosperma parvifolium ("ipequeá"). Espécies de uso medicinal Jacaranda jasminoides ("carobinha"), Pyrostegia venusta ("cipó-cravo"), Solanum paniculatum ("jurubeba"), Pseudobombax grandiflorum ("paina"), Eugenia uniflora ("pitanga"), Smilax hilariana e Smilax rufescens ("salsaparrilha")" (Kneip et al. 1995).

Algumas espécies vivem hoje sobre o próprio sambaqui da Beirada como Schinus terebinthifolius, Sideroxylon obutusifolium, Senna pendula, Astronium graveolens, Manihot tripartida, Clusia fluminensis, entre outras.

b) Identificação da flora utilizada pelo homem pré-histórico através das análises antracológicas dos restos de carvões coletados nos sambaquis da Beirada e Pontinha.

Das espécies identificadas por Kneip et al. (1995), alguns elementos foram reconhecidos pelas análises antracológicas como Aspidosperma sp, Sideroxylon aff. obtusifolium, Pouteria sp. e várias espécies de Myrtaceae ${ }^{7}$. Scheel-Ybert observa ocorrência de elementos de floresta e de mangue, predominando, entretanto, a vegetação de restinga aberta com as espécies acima reconhecidas, e ainda cf. Tapirira, Maytenus sp., Erythroxylum sp., Lauraceae, Byrsonima sp., Rheedia sp., Rapanea sp., entre outras. Observa ainda que os sambaquis analisados apresentaram fragmentos de coquinhos

\footnotetext{
${ }^{7}$ Espécies citadas e publicadas em Scheel-Ybert (1999, 2000). Scheel-Ybert (1999) e Fonseca-Kruel \& Peixoto (2004) registraram estas mesmas espécies de uso passado e presente nesta região e ainda acrescentaram as anonáceas (Annona, Duguetia), bromeliáceas (Ananas, Bromelia), crisobalanáceas (Chrysobalanus), entre outras. Ambos os estudos salientam Sideroxylon obtusifolium, como um caso interessante, pois tanto no passado como no presente, este é um taxon abundante e útil.
}

carbonizados, sementes e resíduos de tubérculos de monocotiledôneas (provavelmente gramíneas, ciperáceas e inhames - Dioscorea sp.), estes últimos assinalados pela primeira vez em sambaquis. Aliás, a presença de coquinhos carbonizados constituem uma constância em sítios pré-históricos, o que significa que as palmeiras desempenharam um papel fundamental nas culturas nativas. Gumilla (apud. Lévi-Strauss, op.cit.), ao destacar sua importância observa que a palmeira muriche (Mauritia flexuosa), por exemplo, foi o sustentáculo econômico dos Waurrau. Dela obtinham madeira para suas palafitas, fibras para vestimentas, ornamentos, redes e apetrechos de pescaria, goma para fazer pão, seiva para produzir vinho, frutos para uma espécie de bebida, folhas para cestos, extraindo também grandes lagartas comestíveis dos troncos em decomposição.

Embora a coleta vegetal, não resta dúvida, tenha sido de extrema importância na alimentação do homem pré-histórico, os dados até agora existentes permitem considerar ainda que a pesca e a coleta de moluscos constituíram a base de subsistência das populações pescadoras, coletoras e caçadoras pré-históricas litorâneas ${ }^{8}$. Os sambaquis representam documentos importantes para a compreensão da evolução da paisagem no período Holoceno, assim como para a compreensão das relações homem e meio. A harmonia existente no passado entre o homem e a natureza resultou de um relacionamento dialético que durou alguns milênios.

\footnotetext{
${ }^{8}$ Scheel-Ybert (1999) compartilha a idéia de que os sambaquieiros do sudeste do Rio de Janeiro foram, por muito tempo, considerados quase que exclusivamente como "comedores de moluscos". Mais recentemente, a pesca tem sido reconhecida como mais importante do que a coleta de moluscos em sua dieta, mesmo quando os restos de conchas são aparentemente predominantes na estratigrafia do sítio. Já a coleta de vegetais, embora implicitamente reconhecida, é frequentemente vista como uma atividade secundária, e a sua contribuição para a dieta é considerada como praticamente negligenciável. A autora salienta que uma alimentação baseada na coleta de moluscos, caça e pesca deixa muitos vestígios materiais no sítio arqueológico, ao contrário da coleta de vegetais. Não podendo ser provado, o consumo de vegetais é geralmente subestimado em favor de dietas que deixam vestígios mais visíveis no sedimento arqueológico.
} 


\section{REFERÊNCIAS BIBLIOGRÁfICAS}

Ferreira, A. M. M.; Oliveira, M. V. O.; Ferreira, J. A. N. \& Kneip, L. M. 1992. Formações superficiais, quaternárias e a atuação de grupos pré-históricos em Saquarema, RJ: uma síntese interpretativa. Congresso Brasileiro de Geologia. Boletim de Resumos Expandidos 1: 97-98.

Fonseca-Kruel, V. S. \& Peixoto, A. L. 2004. Etnobotânica na Reserva Extrativista Marinha de Arraial do Cabo, RJ, Brasil. Acta Botanica Brasilica 18(1): 177-190.

Kneip, L. M. 1979. Pesquisas de salvamento em Itaipu, Niterói, Rio de Janeiro. Itaipu Companhia de Desenvolvimento Territorial, Niterói. Pp. 3-30.

Kneip, L. M.; Araujo, D. S. \& V. S. Fonseca. 1995. Áreas de exploração de recursos abióticos e bióticos das populações préhistóricas de Saquarema, RJ. Documento de Trabalho, Série Arqueologia 3: 3-12.

Kneip, L. M. \& Marques, J. S. 1975. O sambaqui do Forte: relações com depósitos eólicos e marinhos (Cabo Frio, RJ - Brasil). An. Acad. Bras. Cienc. 47: 99-111.

Lee, R. B. 1968. What hunters do for a living, or how to make out on scarce resources. In: Lee, R. B. \& Devore, J. (eds.). Man the hunter. Aldine Publishing Co., Chicago. Pp. 30-48.
Melhem, T. S. 1978. Palinologia suas aplicações e perspectivas no Brasil. Coleção Museu Paulista, Série Ensaios 2: 333-368.

Scheel-Ybert, R. 1998. Reconstitution paléoenvironnmentale et relations homme/milieu sur le littoral sud-est du Brésil à l'holocène supérieur. d'Après l'Analyse Anthrocologique de Sambaguis. Tese de Doutorado. Universite Montpellier II, 209p.

Scheel-Ybert, R. 1999. Paleoambiente e paleontologia de populações sambaquieiras do sudeste do estado do Rio de Janeiro. Revista do Museu de Arqueologia e Etnologia 9: 43-59.

Scheel-Ybert, R. 2000. Vegetation stability in the Southeastern Brazilian coastal area from 5500 to $1400{ }^{14} \mathrm{C}$ yr BP deduced from charcoal analysis. Review of Palaeobotany and Palynology 110: 111-138.

Scheel-Ybert, R. 2001. Man and vegetation in Southeastern Brazil during the late holocene. Journal of Archaeological Science 28: 471-480.

Strauss, C. L. 1986. O uso das plantas silvestres da América do Sul tropical. In: Ribeiro, B. G. (coord.). Suma Etnológica Brasileira. 1. Etnobiologia. Vozes, Petrópolis. Pp. 29-46.

Tenório. M. C. 1991. A importância da coleta de vegetais no advento da agricultura. Dissertação de Mestrado. IFCS/UFRJ, Rio de Janeiro, 216p. 